\title{
Sempre serei sua mãe: Iuto e ressignificação de mães de crianças e adolescentes em tratamento oncológico
}

\author{
I will always be your mother: grief and reframing \\ of mothers of children and adolescents undergoing \\ cancer treatment
}

\author{
Siempre seré tu madre: duelo y redefinición de \\ madres de niños y adolescentes en tratamiento \\ contra el cáncer
}
Tamires Coelho Frasson ${ }^{1}$ (i) Amanda Castro ${ }^{2}$ (1) Gabriela Pereira Vidal ${ }^{3}$ (1) 1,2Universidade do Extremo Sul Catarinense (Criciúma). Santa Catarina, Brasil. tamiresfrasson@hotmail.com, amandacastrops@gmail.com
${ }^{3}$ Autora para correspondência. Universidade Federal de Santa Catarina (Florianópolis). Santa Catarina, Brasil. gabrielavidaal@gmail.com

\begin{abstract}
RESUMO | INTRODUÇÃO: O luto é um processo de ajustamento à perda, seja ela antecipatória ou não, visando a construção de uma realidade diferente da imaginada. OBJETIVO: O presente artigo tem como objetivo compreender como mães de crianças e adolescentes em tratamento oncológico ressignificaram a vida diante do luto do filho. MÉTODOS: Foi realizado um estudo de campo, qualitativo e descritivo com cinco mães que vivenciam/vivenciaram o processo de luto do filho, no mínimo há um ano, sendo o filho criança ou adolescente, que esteve em tratamento oncológico. O instrumento utilizado para coleta de dados foi a entrevista semiestruturada. RESULTADOS: Os resultados obtidos indicam que a experiência do luto para essas mães se caracteriza por um processo de transformação e adaptação singular. As principais estratégias encontradas por elas para o enfrentamento do luto que contribuíram positivamente para ressignificar a perda foram: o apoio dos familiares e amigos; compartilhar sentimentos e experiências com outras mães enlutadas; voltar a trabalhar; perpetuar a memória do filho falecido; uma nova gravidez; guardar objetos do filho perdido; modificar espaços da casa; a espiritualidade; e a realização de sonhos próprios e do filho que faleceu. CONCLUSÃo: Foi possível observar que o processo de ressignificação é carregado de dor e dificuldade, além de tristeza, culpa e outros sentimentos negativos. Destaca-se a importância nesse processo do apoio de familiares, amigos e instituições, além da espiritualidade e busca por novos momentos de vida.
\end{abstract}

PALAVRAS-CHAVE: Luto. Maternidade. Câncer. Crianças. Adolescentes.

ABSTRACT | INTRODUCTION: Mourning is a process of adjusting to loss, whether anticipatory or not, aiming at building a reality different from the one imagined. OBJECTIVE: This article aims to understand how mothers of children and adolescents undergoing cancer treatment have re-signified life in the face of their child's grief. METHODS: For this purpose, qualitative research was carried out with five mothers experiencing / experienced the child's mourning process, at least one year ago, the child being a child or adolescent, who was undergoing cancer treatment. The instrument used for data collection was the semi-structured interview. RESULTS: The results obtained indicate that the experience of mourning for these mothers is characterized by a unique process of transformation and adaptation. The main strategies they found to cope with grief, which contributed positively to redefining the loss were: the support of family and friends; sharing feelings and experiences with other bereaved mothers; back to work; perpetuating the memory of the deceased child; a new pregnancy; guarding objects of the lost child; modify spaces in the house; spirituality; the realization of own dreams and the son who passed away. CONCLUSION: It was possible to observe that the reframing process is fraught with pain and difficulty, in addition to sadness, guilt, and other negative feelings. The importance of supporting family members, friends, and institutions in this process is highlighted, in addition to spirituality and the search for new moments in life.

KEYWORDS: Bereavement. Maternity. Cancer. Children. Adolescents. 
RESUMEN | INTRODUCCIÓN: El duelo es un proceso de adaptación a la pérdida, anticipatoria o no, con el objetivo de construir una realidad diferente a la imaginada. OBJETIVO: Este artículo tiene como objetivo comprender cómo las madres de niños y adolescentes en tratamiento contra el cáncer dieron un nuevo sentido a sus vidas ante el dolor de sus hijos. MÉTODos: Se realizó un estudio de campo, cualitativo y descriptivo con cinco madres que han vivido / vivido el proceso de duelo de su hijo durante al menos un año, siendo el niño un niño o adolescente, que había estado en tratamiento contra el cáncer. El instrumento utilizado para la recolección de datos fue la entrevista semiestructurada. RESULTADOS: Los resultados obtenidos indican que la experiencia de duelo de estas madres se caracteriza por un proceso de transformación y adaptación singular. Las principales estrategias que encontraron para afrontar el duelo que contribuyeron positivamente a replantear la pérdida fueron: el apoyo de familiares y amigos; compartir sentimientos y experiencias con otras madres en duelo; volver al trabajo; perpetuar la memoria del niño fallecido; un nuevo embarazo; guardar las pertenencias del niño perdido; modificar espacios en la casa; espiritualidad; y la realización de sus propios sueños y el del hijo que murió. ConcLusıón: Se pudo observar que el proceso de resignificación está plagado de dolor y dificultad, además de tristeza, culpa y otros sentimientos negativos. En este proceso se destaca la importancia del apoyo de familiares, amigos e instituciones, además de la espiritualidad y la búsqueda de nuevos momentos en la vida.

PALABRAS CLAVE: Duelo. Maternidad. Cáncer. Niños. Adolescentes.

\section{Introdução}

O câncer é reconhecido como uma doença crônico degenerativa, em que há o crescimento celular desordenado e invasivo. Atualmente, apresenta-se como um problema de saúde pública, que vem crescendo concomitantemente diante do aumento da expectativa de vida da população e das transformações que ocorreram nas últimas décadas, relacionadas à urbanização acelerada e mudanças nos hábitos da população (Paula et al., 2018). O câncer em crianças e adolescentes é considerado raro quando comparado com os tumores de adultos, representa de 2 a 3\% entre todos os tumores malignos, com uma tendência maior de cura, pois respondem melhor aos métodos terapêuticos atuais, porém, são mais agressivos e invasivos, apresentando um crescimento rápido em relação aos casos que acometem outras idades (Barros et al., 2017). Essa resposta melhor ao tratamento se dá pelo fato que os tumores em crianças e adolescentes são predominantemente de origem embrionária, sendo assim, constituem-se de células indiferenciadas. Os tipos mais comuns de tumores diagnosticados nesse grupo de idade são: as Leucemias que afetam os glóbulos brancos, os tumores do Sistema Nervoso Central e os Linfomas, que atingem o sistema linfático do sujeito (Instituto Nacional do Câncer, 2020).

Receber um diagnóstico de câncer em uma criança ou adolescente, afeta todos os membros do âmbito familiar, comumente ocasionando desgaste emocional com potencial para desestruturá-la profundamente, pois altera papéis na dinâmica familiar e os sentimentos de insegurança, medo, desespero e angústia passam a fazer parte da rotina diária da família (Alves et al., 2016). Santos e Silva (2016) corroboram com os autores quando afirmam que o câncer infantojuvenil e sua forma de tratamento, têm um impacto sistêmico sobre a organização familiar, tornando-a vulnerável ao sofrimento psíquico.

Tal sofrimento psíquico se amplia em razão do pensamento social que relaciona o diagnóstico da doença com a certeza da morte. Nesse contexto, o apoio oferecido pela equipe de saúde, no momento de comunicar e explicar a condição enferma à família deve ser adequado já que a compreensão implicará nas condições emocionais durante o tratamento ou até mesmo no acontecimento da morte, favorecendo a aceitação do processo (Santos \& Silva, 2016).

O luto é um processo natural, interno e necessário após o rompimento de vínculos e perdas significativas. A retirada da figura de apego afeta estruturas psicológicas e abala aspectos psíquicos. Para o enfrentamento e ressignificação deste processo, o sujeito busca meios para lidar com a dor e o sofrimento. Kubler-Ross (1996), sistematizou o processo de luto em cinco fases ou estágios: negação, raiva, barganha, depressão e aceitação. No estágio da negação, o enlutado está frente a uma realidade inaceitável, na tentativa de fugir desta. A raiva, segundo estágio, é repleta de sentimentos de revolta e ressentimento em relação a perda. Na fase de barganha há uma tentativa de negociação em relação a crença do sujeito, na possibilidade de que um ser superior mude a realidade. 
A depressão é um momento de preparação, na qual a pessoa volta-se a seu mundo interno e sua impotência diante do ocorrido. Por fim, a aceitação é o momento no qual o sujeito aceita e encerra sua luta contra a realidade do luto (Kubler-Ross, 1996). Essas estratégias de enfrentamento são necessárias para elaboração física e psíquica, relacionando-se com a capacidade do ser humano de transformação e reestruturação após momentos difíceis (Gonçalves \& Bittar, 2016). A experiência do luto é singular, o modo de lidar com o fato depende dos recursos internos e das inúmeras interrelações que o sujeito possa realizar na interação com o meio ambiente (Alves et al., 2016).

O câncer por ser uma doença considerada complexa, faz com que os pais vivenciem uma espécie de luto antes da morte propriamente dita, chamado de luto antecipatório (Kovács, 2009), principalmente diante de alguns tratamentos que vão ocasionando perdas simbólicas (Coelho Filho \& Lima, 2017). Nesse sentido, Coelho Filho e Lima (2017), elucidam que o luto antecipatório ocorre com os familiares e com os próprios pacientes em si, geralmente em situações de doença grave e de longos períodos de tratamentos. Caracteriza-se por um luto, permeado por diversos comportamentos, desde a negação, culpa, angústia e aceitação. Entretanto, o luto antecipatório nem sempre é algo ruim, podendo estreitar a relação entre os pais e filhos, possibilitando despedidas, mudanças de comportamentos afetivos e uma preparação melhor para o momento da morte e sua aceitação.

Segundo Arantes (2019), durante a doença de uma pessoa querida essa experiência de luto antecipatório, proporciona aos familiares experimentar reflexões de como será a vida daquela pessoa futuramente, ou como será viver sem ela. Nesse tempo de elaboração da perda antecipada, os pais têm oportunidades maravilhosas de demostrar mais afeto, carinho, cuidado e perdão (Arantes, 2019).

Quando o assunto é morte na infância ou adolescência, a dificuldade de aceitação torna-se ainda maior. Criança é sinônimo de alegria, amor, desenvolvimento e não de terminalidade, desta forma, se tem a idealização que a vida desse sujeito não se cumpriu e foi ceifada prematuramente. Nesse sentido, a morte nessas fases da vida frequentemente gera comoção e perplexidade (Mazer-Gonçalves et al., 2016).
Deste modo, ocorre a sensação de ruptura da ordem natural dos acontecimentos. Para Mazer-Gonçalves et al. (2016, p. 14) "Esse contexto parece destoar do que o senso comum considera como uma realidade plausível, uma vez que é difícil compreender que o ciclo vital se inverteu, já que crianças também morrem".

O processo de luto é um trabalho de ajustamento à perda, marca o início de uma trajetória a ser percorrida, na construção de uma realidade diferente daquela feita com expectativas e sonhos quanto ao futuro de um filho que agora já não está mais junto desses pais. Não existe um método para abrandar a dor. Muitos buscam encontrar diante do sofrimento alguma esperança, conforto e alternativas de vida que tornem essa etapa de adaptação menos dolorida, encontradas não apenas nos âmbitos pessoais e familiares, mas também nas esferas social e cultural (Pereira et al., 2018). “( . . . ) é necessário que os pais possam construir uma nova realidade sem a criança, desconstruindo todas as expectativas em relação a seu desenvolvimento e crescimento. O luto parental é complexo, não linear e contínuo ( . . . )" (Andrade et al., 2017, p. 22).

Na perspectiva de Bromberg (2000), o processo de luto pode envolver quatro fases, que não ocorrem necessariamente de forma rígida e na sequência, uma vez que a individualidade e subjetividade do indivíduo são diferentes no luto. A primeira fase seria a do Entorpecimento, em que a pessoa expressa o choque e descrença a notícia da perda, a duração pode ser de poucas horas ou de muitos dias, o enlutado sente-se perdido e atordoado. Outra fase seria a do Anseio e Protesto, onde existe uma busca frequente pela pessoa perdida, comumente, sente-se raiva por não conseguir restabelecer o contato com a pessoa que morreu, podendo haver crises de profunda dor e espasmos incontroláveis de choro, nesta fase há uma preocupação obsessiva com lembranças, pensamentos e objetos do falecido. Em seguida, está a fase da Desorganização e Desespero, o enlutado deixa de procurar a pessoa perdida o tempo todo e reconhece a perda. Nessa fase, a pessoa pode manifestar-se apática e deprimida, isola-se e perde o desejo pela vida social. Por último, a fase de Reorganização, em que se dá o início da aceitação da perda, começa a ocorrer o retorno da independência e da iniciativa, mesmo sendo comum a volta de sintomas que haviam cedido, principalmente em datas que trazem muitas lembranças, como dias de nascimento e morte (Bromberg, 2000). 
É de extrema importância ressaltar que a morte do filho também interfere na identidade desses pais. A identidade se constrói a partir dos grupos que o indivíduo se identifica enquanto sujeito. A família é o primeiro grupo social mais importante, os papéis exercidos dentro deste grupo são significativos para a constituição da identidade. Deste modo, quando nasce um filho, nasce também um papel de pai e mãe. Na morte do filho, essa relação que antes havia sido estabelecida é interrompida, a identidade passa por transformações, evidenciando sentimentos ambivalentes. O papel de pai e mãe passa a ser substituído por uma identificação não denominada, principalmente nos casos em que o filho era o único (Coelho Filho \& Lima, 2017).

A tentativa de reconstruir e organizar a vida são partes do trabalho de luto. A mudança da rotina da família posterior à morte é algo que demanda muito esforço, visto que os dias geralmente são carregados de uma série de sentimentos e incertezas. "Os pais que passam por essa experiência vivem um momento de crise e precisam adaptar-se à nova situação, sendo de fundamental importância que tenham liberdade para viver e expressar o seu pesar e luto" (Pereira et al., 2018, p. 423). Na teoria Freudiana como descrevem Laplanche e Pontalis (2001), ao passar pelo processo de perda, o indivíduo vivencia uma ruptura no investimento objetal, emergindo a pulsão de morte. Para os autores, esse conceito caracteriza-se por uma luta contínua, inexorável que leva a procurar paz e repouso, não importa por qual meio, sob qualquer forma, que se contrapõem a de vida, tendendo à autodestruição

Para retomar a vida e encontrar um sentido para essa, os pais precisam expressar seus sentimentos, agindo espontaneamente. Aceitar a realidade da morte e experimentar a dor do momento é indispensável para ressignificar a morte. É necessário se reorganizar psiquicamente e com as relações interpessoais para elaborar a morte de um filho. Ajustar-se à nova rotina, integrar aspectos do ente querido falecido em sua própria identidade, encontrando significado na perda para iniciar novas relações, são meios que tendem a ajudar o enlutado a reconciliar-se com a vida após a perda (Andrade et al., 2017).

Por outro lado, a morte de alguém que se ama pode ser visualizada como um acontecimento que favorece o crescimento pessoal dos pais, isso é possível quando um sentido é atribuído à perda, esse processo auxilia para lidar de forma mais eficaz com as dores e medos. Quando as perdas são prematuras, o indivíduo fica como se o seu mundo tivesse "acabado", necessitando ainda mais do encontro de sentido para aquela perda (Franqueira et al., 2015).

Como já mencionado, o apoio social e também familiar é essencial, um ambiente que seja acolhedor transmitindo confiança ao enlutado concede condições para agir de forma criativa e espontânea. Segundo Andrade et al. (2017), o trabalho do luto busca ressignificar a perda, elaborar os sentimentos para que essa dor não comprometa a continuidade da vida.

Sobre o suporte familiar, Franqueira e Magalhães (2018), em pesquisa realizada com dez pais que vivenciaram o luto parental, apontaram que o apoio informal de familiares e amigos é crucial, principalmente nos dias seguidos à perda. Embora essas pessoas não encontrem respostas para justificar uma perda tão significativa, o fato de estarem próximos e disponíveis fornece conforto aos pais enlutados, segundo o estudo. A pesquisa esclarece que outra maneira de diminuir o isolamento e a dor é o contato desses pais com outros pais enlutados. Para eles, somente quem passou por perdas semelhantes, consegue entender a natureza da perda do filho, tornando-se uma forma propícia de acolhimento. Possibilitar que os pais sejam ouvidos na expressão de seus sentimentos ao compartilhar com os outros pais, permite que as memórias dos filhos permaneçam vivas, por isso a maioria dos pais enlutados têm o desejo de falar sobre a vida de seus filhos (Franqueira \& Magalhães, 2018).

Além da família, amigos e redes de suporte entre pares, outras pesquisas remetem a espiritualidade como fonte de apoio, desde o tratamento até o processo de luto. Alves et al. (2016), por exemplo, entrevistaram 8 pais de crianças com câncer na condição de impossibilidade terapêutica e em seus resultados foi evidenciado que as crenças religiosas e espirituais "influenciam a tomada de decisão, correlacionadas com a qualidade de vida diante do câncer, as necessidades espirituais proporcionam apoio psicológico e espiritual em todos os envolvidos no processo de morte" (Alves et al., 2016, p. 6). Almeida e Mautoni $(2015$, p. 58) salientam que "a espiritualidade se refere 
a um bem-estar consigo mesmo e com o outro, por acreditar que há algo que transcende o ser humano". O sofrimento faz com que as pessoas busquem algo a mais para se confortar e continuar a vida, a espiritualidade é de grande valia para que os pais se tornem mais resilientes e percorram o caminho do luto com mais equilíbrio emocional (Almeida \& Mautoni, 2015).

Ao falar sobre a resiliência, percebe-se o quanto o conceito é importante dentro da realidade do luto. Angst (2009) descreve que o termo resiliência se originou da física e da engenharia, sendo que um determinado material era chamado de resiliente quando a energia de deformação máxima que ele é capaz de armazenar não gera nele deformações permanentes. Pesquisadores das ciências humanas entenderam que o termo também poderia ser utilizado com os seres humanos, referindo-se à capacidade que possibilita ao indivíduo prevenir, minimizar ou superar os efeitos nocivos das adversidades, saindo dessa situação não ileso, mas fortalecido e transformado para crescimento pessoal (Angst, 2009). Isso não significa que o resiliente não sofra, ele sofre, sente a dor da perda, se entristece. Não se trata de uma pessoa invulnerável, o que existe nesse ser é uma esperança de que a vida precisa continuar, é o querer levantar, dar a volta por cima reorganizando a construção, desconstrução e reconstrução de significados após um evento traumático como a perda do filho (Almeida \& Mautoni, 2015).

Sobre os projetos sociais e seu papel no enfrentamento do luto, Freitas e Michel (2014) realizaram uma pesquisa com mães enlutadas onde o engajamento nesses projetos relacionados ao filho, na qual para as participantes estes foram significativos e de valor na vivência do luto. Para os autores, esse comprometimento, pode ser um fator de enfrentamento para mães enlutadas, uma vez que ao lidarem com a realidade da morte elas se permitem ressignificar o lugar de seus filhos em suas vidas, além de configurarem novos laços sociais.

Percebe-se então que apesar do luto ser sofrido e que perder alguém muito querido causa uma dor avassaladora, o enlutado pode encontrar forças para continuar a vida, percorrendo um novo caminho, trazendo consigo as lembranças de alguém amado em que somente o corpo físico partiu (Almeida \& Mautoni, 2015).
A médica Ana Claudia Quintana Arantes (2019), especialista em Cuidados Paliativos, relata que passar por uma perda pode fazer o indivíduo perceber o tamanho do amor que se é capaz sentir por alguém, a pessoa que morre não leva consigo a história de vida que compartilhou com aqueles que conviveram com ela, não há uma morte absoluta no sentido de desintegrar todas as dimensões de um ser humano, quando a morte chega, tudo aquilo que foi vivenciado continua vivo nas memórias, sendo o primeiro passo aprender a viver com essa ausência. Para a autora, a dor do luto é proporcional à intensidade do amor que foi compartilhado durante a relação e é por meio desse amor que o ser humano consegue se reconstruir.

Essa saída para uma nova vida ou para findar o luto não possui um tempo determinado. Ressignificar a perda, não implica em afirmar que os pais apagarão da memória o filho perdido e que nunca mais irão chorar ou sentir saudade, porém as reações ganham outra intensidade e significado, é um movimento de perceber que se pode viver de novo, concentrando as energias em toda a vida e não apenas na mágoa e na dor (Kubler-Ross, 1996).

Nesse sentido, justifica-se a importância deste estudo diante de sua relevância científica, visto que são poucos os estudos recentes que relacionam o luto na perda de um filho que esteve em tratamento oncológico, bem como as contribuições positivas para a saúde mental da pessoa enlutada. Diante disso, o objetivo desta pesquisa foi compreender como mães de crianças e adolescentes em tratamento oncológico ressignificaram a vida diante do luto do filho.

\section{Método}

O presente estudo foi conduzido pela epistemologia e metodologia qualitativa, na qual os dados são coletados a partir de interações sociais, preocupandose com o mundo empírico em seu ambiente natural, oferecendo a possibilidade de investigar processos subjetivos como a vivência, as expectativas e os aspectos emocionais do sujeito da pesquisa (Zanella, 2013). A escolha por essa abordagem se deu pela necessidade de uma base metodológica que permitiria esse contato com a subjetividade dos fenômenos pesquisados 
A pesquisa também é classificada como descritiva, pois um dos objetivos específicos caracterizou-se em descrever como ocorreu/ocorre a ressignificação após a perda do filho. Segundo Gil (2008, p. 28), "As pesquisas deste tipo têm como objetivo primordial a descrição das características de determinada população ou fenômeno ou o estabelecimento de relações entre variáveis".

Para alcançar todos os objetivos propostos, adotouse como estratégia metodológica o estudo de campo, deste modo, as informações foram extraídas em contato direto com o objeto de estudo. De acordo com Gil (2008), o estudo de campo pretende buscar a informação diretamente com a população pesquisada, o pesquisador vai até o local onde os fenômenos ocorrem, ou ocorreram.

Participaram da pesquisa 5 mães que vivenciam/ vivenciaram o processo de luto do (a) filho (a) no mínimo há um ano, sendo o (a) filho (a) criança ou adolescente, que esteve em tratamento oncológico. Para isso, foram adotados os seguintes critérios de inclusão: ser o (a) genitor (a) de uma criança ou adolescente que esteve em tratamento oncológico e faleceu no mínimo há um ano; possuir capacidade cognitiva e de comunicação preservadas para responder a entrevista semiestruturada e concordar livremente com a participação, assinando o Termo de Consentimento Livre e Esclarecido - TCLE. O acesso às participantes ocorreu via rede de contatos da pesquisadora, seguindo a técnica metodológica Bola de Neve. Conforme Vinuto (2014), esse tipo de técnica é uma forma de amostra não probabilística, que utiliza redes de referência, ou seja, não é possível determinar a probabilidade de seleção de cada participante na pesquisa, sendo útil para estudar determinados grupos difíceis de serem acessados. Para o início da amostragem a partir dessa técnica, foram localizados na população geral os primeiros indivíduos com o perfil desejado para a pesquisa, denominados pelo autor de "sementes". Esses participantes indicaram novos contatos para o pesquisador tatear o grupo a ser pesquisado. Solicitou-se que as pessoas indicadas pelas sementes indicassem novos contatos com as características desejadas, a partir de sua própria rede pessoal, e assim sucessivamente até obter o número de participantes necessário. Destaca-se que foram indicadas através da técnica Bola de Neve apenas o contato de outras mães. Dessa forma, não foi possível encontrar pais para a pesquisa, sendo realizada somente com mães.

O instrumento utilizado para coleta de dados foi a entrevista semiestruturada, por se mostrar mais adequada para obter as informações que a pesquisadora desejava. Zanella (2013) ressalta que nesse tipo de entrevista, o entrevistado fica livre para responder sobre o tema, sem a necessidade de uma sequência de perguntas completamente padronizadas. A entrevista semiestruturada abrangeu os seguintes temas: relato da experiência do dia posterior a morte do filho; alteração da rotina; estratégias de enfrentamento do luto; modificação do espaço; saúde psicológica atual; identificação de projetos futuros; Identificação de vínculos significativos; o que dizer para alguém que acabou de perder o filho em razão do câncer; saúde psicológica atual; projeção para cinco anos; a ótica das mães sobre o que os filhos diriam se vissem como estão atualmente. A duração de cada entrevista foi de aproximadamente 40 minutos, realizadas nas casas das participantes, ou local de preferência das entrevistadas. As entrevistas foram gravadas e transcritas.

Essa pesquisa foi submetida ao Comitê de Ética e Pesquisa (CEP) da Universidade do Extremo Sul Catarinense em respeito à resolução $n^{\circ}$ 01/2014/ CONSU e aprovada pelo parecer consubstanciado $n^{\circ}$ 3.542.697. As participantes foram informadas sobre a participação facultativa e possibilidade de desistência a qualquer momento da pesquisa, sem implicação de ônus ou bônus. Todas as participantes que concordaram em participar assinaram um Termo de Consentimento Livre e Esclarecido onde os objetivos e aspectos da participação na pesquisa foram explicados. Caso as entrevistas ocasionassem reações emocionais, as participantes seriam acolhidas e encaminhadas para serviço psicológico gratuito da Universidade do Extremo Sul Catarinense - UNESC. 
Os dados foram analisados por meio da análise de conteúdo de Bardin (2011), que se refere a um método de categorias que permite a classificação dos componentes do significado da mensagem, ou seja, visa obter por procedimentos sistemáticos e objetivos de descrição do conteúdo das mensagens, indicadores que permitam a inferência de conhecimentos relativos às condições de produção destas mensagens (Bardin, 2011).

A análise de conteúdo de Bardin (2011) é organizada em três fases que são: pré análise; exploração do material e tratamentos dos resultados - a interferência e a interpretação. A pré-análise é a fase de organização, estabelecese um esquema de trabalho que deve ser preciso, com procedimentos bem definidos, embora flexíveis. Segundo a autora trata-se de leitura "flutuante", se caracteriza primeiro contato com os documentos que serão analisados, a escolha deles, a formulação das hipóteses e objetivos e também é elaborado os indicadores que fundamentarão a interpretação final. A fase de exploração do material compreende a escolha de unidades de registro e a escolha de categorias ou classes que reúnem um grupo de elementos em razão de características comuns. A terceira e última fase é o tratamento e interpretação do material, onde são sintetizados e selecionados os resultados obtidos para fins teóricos ou pragmáticos, com isso, através da interpretação dos resultados pode-se identificar questões para iniciar uma nova análise (Bardin, 2011).

\section{Resultados e discussão}

\section{Caracterização das participantes}

Tabela 1. Caracterização das participantes da pesquisa

\begin{tabular}{|c|c|c|c|c|c|}
\hline Nome & $\begin{array}{l}\text { Mãe de um } \\
\text { Guerreiro }\end{array}$ & $\begin{array}{l}\text { Mãe em } \\
\text { Busca de } \\
\text { Justiça }\end{array}$ & $\begin{array}{l}\text { Mãe de uma } \\
\text { Flor }\end{array}$ & $\begin{array}{l}\text { Mãe de um } \\
\text { Sapeca }\end{array}$ & $\begin{array}{c}\text { Mãe de uma } \\
\text { Futura Psicóloga }\end{array}$ \\
\hline Idade da Mãe & 33 anos & 42 anos & 37 anos & 37 anos & 36 anos \\
\hline Renda Familiar & $\mathrm{R} \$ 360,00$ & $\mathrm{R} \$ 2.700,00$ & $R \$ 1.500,00$ & $\mathrm{R} \$ 3.000,00$ & $R \$ 2.500,00$ \\
\hline Escolaridade & $\begin{array}{l}\text { Cursando Téc. } \\
\text { Enfermagem }\end{array}$ & $\begin{array}{l}\text { Técnica em } \\
\text { Enfermagem }\end{array}$ & $\begin{array}{l}\text { Técnica em } \\
\text { Enfermagem }\end{array}$ & $\begin{array}{l}\text { Ensino } \\
\text { Médio } \\
\text { Completo }\end{array}$ & $\begin{array}{c}\text { Cursando Téc. } \\
\text { Design de } \\
\text { Interiores }\end{array}$ \\
\hline $\begin{array}{l}\text { Sexo do } \\
\text { Filho (a) }\end{array}$ & Masculino & Masculino & Feminino & Masculino & Feminino \\
\hline Tipo de Câncer & Neuroblastoma & "Na cabeça" & Neuroblastoma & Leucemia & Osteossarcoma \\
\hline $\begin{array}{l}\text { Data de } \\
\text { Falecimento }\end{array}$ & $02 / 04 / 2016$ & $01 / 02 / 14$ & $12 / 12 / 2016$ & $20 / 07 / 17$ & $22 / 03 / 17$ \\
\hline $\begin{array}{l}\text { Idade do } \\
\text { filho (a) }\end{array}$ & 02 anos & 03 anos & 05 anos & 06 anos & 12 anos \\
\hline
\end{tabular}


Na tabela 1, é possível perceber que foram gerados codinomes para as mães entrevistadas. Esses nomes foram pensados em função do contexto de fala de cada participante. A entrevistada denominada "Mãe de um Guerreiro" traz seu filho como um herói pois, "deixou um legado por meio da sua força". A participante "Mãe em Busca de Justiça" relata em seu discurso a ideia de que a morte do seu filho pode ter sido consequência de negligência médica. A "Mãe de uma Flor" abordou o desejo de fazer um jardim de flores mesmo após a morte da filha, tendo em vista que as duas costumavam plantar flores juntas. A "Mãe de um Sapeca" apresenta lembranças em que o mesmo estava ativo, alegre e que a "casa parecia cheia". A "Mãe de uma Futura Psicóloga" lembrou da filha como mediadora de conflitos e que além de gostar de conversar, tinha interesse por psicologia.

A partir do relato de experiências das mães, tornase importante enfatizar em qual fase do processo de luto as mães se encontram. São muitos os autores que estudam sobre as fases do luto, por isso, elas podem apresentar nomenclaturas e características específicas diferentes. Neste estudo apresentaremos as fases na perspectiva de Maria Helena Pereira Franco Bromberg (2000).

Ao analisar as entrevistas das cinco mães, percebe-se que todas estão na fase de Reorganização (Bromberg, 2000). A vida encontra-se reorganizada tanto de forma interna quanto externa, já reconhecem a perda e são capazes de investir em novos planos futuros, mesmo alguns desses tendo relação direta com o fiIho falecido. Observou-se que as mães conseguiram relatar sobre suas experiências sem expressar tanta tristeza e dor, mas com uma linda saudade que segundo elas, jamais cessará. Em alguns momentos relatados identifica-se sintomas de outras fases, segundo a autora referenciada, isso é algo normal e esperado frente a alguns acontecimentos.

Em relação aos dados sociodemográficos é possível perceber que as participantes apresentaram idades entre 33 e 42 anos. Renda familiar de até três salários mínimos, sendo que a maioria cursava ou já havia concluído o curso Técnico em Enfermagem. Três dos filhos eram do sexo masculino, em geral estavam com idades entre 02 e 12 anos quando faleceram, sendo a data de falecimento no máximo há 06 anos.
A maioria das participantes optou por uma formação voltada para o cuidado em saúde, como se essa fosse uma estratégia de enfrentamento no processo de luto. Não foram encontrados estudos científicos na área que comprovem essa hipótese. Entretanto, de acordo com Medina e Takahashi (2003), a escolha por uma carreira profissional ocorre também por meio da ascendência histórica do indivíduo, ou seja, pela influência das experiências que esse teve ao longo da sua vida, sendo motivada por fatores internos, externos, familiares, valores éticos e a capacidade de lidar com frustrações e conflitos. Dessa forma, percebe-se que essas mães suscitaram com suas experiências o desejo genuíno de ajudar e cuidar das pessoas, concretizando através da escolha pelo curso Técnico em Enfermagem, ou ainda pela oportunidade de estar em contato com o ambiente que traz lembranças de momentos com filho amado falecido.

\section{Análise de conteúdo - A maternidade diante do luto}

Através das respostas obtidas na entrevista semiestruturada utilizada como meio de coleta de dados, foi possível analisar oito temas que descrevem como ocorreu a ressignificação do luto para as mães entrevistadas. Sendo eles: dia posterior a morte do filho; alteração da rotina; estratégias de enfrentamento; alteração do espaço da casa; o que dizer para alguém que acabou de perder o filho em razão do câncer; saúde psicológica atual; projeção para cinco anos e a ótica das mães sobre o que os filhos diriam se vissem como as mães estão atualmente.

A seguir será apresentada a análise de conteúdo para contextualização dos elementos da entrevista.

\section{Dia posterior a morte do filho}

Os dias posteriores à morte do filho estão propensos ao intenso sofrimento, negação e períodos de solidão. As genitoras salientaram que não conseguiam comer, dormiam demais, ficaram extremamente tristes e descrentes da realidade. Possivelmente essas mães, em razão da tristeza, não investiam energia em suas vidas e em seu autocuidado. Como demonstram os trechos: “Eu literalmente morri viva ( . . . ) eu morri durante trinta dias, eu fiquei dentro de um quarto só levantava tomava um café preto, fumava, chorava e 
dormia” (Mãe de um Guerreiro). “( . . . ) ficava pensando: é um sonho ainda? Nada passava, tu não tem fome, tu não sente nada" (Mãe em Busca de Justiça).

Esses comportamentos expressados pelas mães após a morte do filho podem referir-se ao conceito de pulsão de morte, da teoria freudiana, no qual a paz e repouso, aparecem como uma contraposição a vida (Laplanche e Pontalis, 2001) e neste caso uma forma de vivenciar o luto. A vivência desse processo depende de muitos fatores, logo, a percepção e compreensão do suporte e apoio para lidar com a situação são cruciais. As participantes relataram que após o falecimento dos filhos receberam os amigos em casa e tiveram a presença da família reunida, o que salienta a importância da rede social de apoio no processo de luto. Conforme os relatos: "A família é muito importante nesse momento ( . . ) por mais que outras pessoas conversem contigo a família te dá o chão para passar por aquilo ali" (Mãe de uma Futura Psicóloga). "Eu lembro assim, domingo o dia que ele faleceu, estavam meus amigos aqui, mas a gente não saiu para nada ( . . . )" (Mãe de em Busca de Justiça).

Os autores Rebelo et al. (2017) evidenciam que na maioria das perdas é natural o enlutado encontrar nas pessoas ao seu redor, familiares, amigos e vizinhos, o apoio às suas necessidades, sejam essas, emocionais, físicas, financeiras ou o auxílio com os demais filhos. Segundo os autores, sempre que existe uma estrutura informal de apoio, com pessoas que estão disponíveis a ouvir e ajudar incondicionalmente a pessoa em luto, sem censurar seus atos, estão criadas as condições para um processo com suporte saudável.

Nesse mesmo contexto, a escuta empática e a compreensão dos sentimentos por outras mães que também perderam seus filhos, foram fundamentais para a saúde mental após a perda. A sociedade em geral ainda apresenta dificuldades de aceitar a morte prematura durante a infância e adolescência e inibe assuntos relacionados, por isso, o vínculo com pessoas que vivenciaram a mesma situação gera um ambiente seguro. Como apresenta o trecho: "E depois as mães né, que perderam seus filhos e deram apoio ( ... ) sempre ajudando. Fica aquele vínculo para vida toda, uma conversar com a outra, por mais que não se vejam" (Mãe de um Sapeca).
De acordo com Franqueira e Magalhães (2018), um espaço de construção de significados e minimização da tristeza ocasionada pela morte, seria estar em contato com outros pais que passaram pela experiência. Muitas pessoas não sabem o que dizer aos enlutados e evitam contato com eles, principalmente nos momentos e dias seguintes à perda. Esses pais entendem a natureza e a dor da perda, normalmente, sabem de que forma acolher e contribuir para o luto saudável.

No que se respeita ao suporte social a nível mais formal, três mães trouxeram a organização não governamental Casa Guido localizada em Criciúma - SC, como indispensável para o momento de dor e os dias tristes. Mesmo com o passar dos anos as mães mantém vínculo com a instituição e tentam de alguma retribuir todo suporte recebido, se envolvendo em trabalhos voluntários para a mesma. Conforme o trecho: "O pessoal da Casa Guido, ficou muito presente, virou tipo uma família, se não fossem eles, todo o apoio, não digo o financeiro, eu digo o apoio psicológico, tudo né? ( . . . ) é uma partezinha dele!" (Mãe de um Sapeca).

A missão da Casa Guido visa "oferecer o amplo apoio humanizado em todo tratamento de crianças e adolescentes com câncer, fortalecido no sentimento de amor incondicional ao próximo na luta pela vida", incluindo suporte psicológico e social estendidos também aos familiares dos pacientes (Guido, 2020). O apoio auxilia na vivência do luto e permite a busca de novos significados e laços sociais.

Perder um filho é uma experiência desorganizadora, percorrer o caminho do luto compartilhando as experiências e dores com outras pessoas contribui para o alívio do sofrimento. Observa-se que nenhuma mãe ficou sem apoio após a perda, o auxílio foi recebido de uma rede acolhedora e sensibilizada com a situação, foram familiares, amigos, instituições, mães que também perderam seus filhos que buscaram compreender as preocupações e fragilidades das mães e deste modo, foram importantes para enfrentar o luto. 


\section{Alteração da rotina}

Três mães trouxeram a ideia de que a falta do filho é sentida pelo silêncio, seja pela ausência da bagunça ou por não ter alguém para acordar todos os dias de manhã.

Antes nós fazíamos tudo junto, ela acordava me chamava, nós tomávamos café, aí era brincar (. .

. ) então, não tem mais aquela bagunça para eu arrumar, não tem mais aquela correria dentro de

casa, eu dizendo para parar de correr que vai se machucar e às vezes, eu estava sentada parecia que eu via passar correndo, mas é coisa da cabeça (... ).

(Mãe de uma Flor)

Por romper a ordem natural da vida, a morte imprevisível do filho é a que mais desestabiliza a rotina do ser humano. Nesse caso, o processo de substituição da presença pela memória do filho dentro do ambiente familiar fica muito mais lento e doloroso. Torna-se difícil lidar com o silêncio que antes quase não existia, com a falta e a saudade de um ser com o qual o vínculo incondicional era estabelecido diariamente. Nos momentos imediatos posteriores à perda, o indivíduo tem suas sensações de segurança, esperança e entusiasmo rompidas drasticamente, o popular "estou sem chão", permanecendo a sensação de vazio absoluto (Agnese et al., 2012).

Duas entrevistadas trouxeram a volta ao trabalho como uma alteração da rotina necessária ao enfrentamento. Enquanto outra mãe tentou voltar a trabaIhar e não conseguiu. Conforme os trechos: "Depois de quatro dias eu fui trabalhar, tentei fixar o máximo que eu podia no trabalho para não pensar muito, porque cada vez que eu pensava qualquer coisa era um choreiro" (Mãe de uma futura Psicóloga). "( . . . ) tentei trabalhar, daí não consegui a minha cabeça não ajudava, o meu emocional não estava legal!" (Mãe de um Guerreiro).

Os dois contextos de falas podem ser analisados através da ótica dos autores Gomes e Gonçalves (2015), quando destacam que durante o trabalho de luto, se o indivíduo for capaz de retirar suas cargas libidinais, ou seja, seus afetos, emoções e desejos das diversas representações e memórias intrapsíquicas do filho perdido, conseguirá direcionar sua energia para outras áreas da vida, inclusive a profissional. Contudo, quando toda energia se encontra hipercatexizada para o filho perdido, torna-se difícil desempenhar outras atividades, como o retorno ao trabalho. Mas, esse é um processo com um desenrolar diferente para cada mãe, quando há a realidade e a confirmação de que o filho não se encontra mais presente fisicamente, o enlutado passa a exigir que grande parte de sua energia seja retirada de suas ligações com o filho amado e deslocada para uma outra pessoa, atividade e dimensões da vida humana, afirmam os autores (Gomes \& Gonçalves, 2015).

Duas mães destacaram dificuldades de dar carinho para um filho após o falecimento do outro. Como se fosse injusto com o filho falecido, tendo em vista que esse não poderia mais receber o seu carinho físico.

Eu falhei até com o meu outro filho, eu não conseguia dar carinho para ele, porque eu pensava que o " $M$ " (filho que morreu) estava vendo e eu pensava: como eu vou dar carinho para um e não vou dar para o outro? Então assim, eu fiquei um tempo sem dar carinho, hoje eu consigo. (Mãe em Busca de Justiça)

Segundo Sanches (2012), quando o vínculo de amor e convivência entre a mãe e o filho se rompe, essa passa a carregar consigo o sentimento de culpa, independente das circunstâncias que levaram à morte, pois acreditam que fracassaram na proteção. Além disso, há o sentimento de culpa moral, por achar que os filhos deveriam viver mais que os pais e principalmente quando dão carinho para os demais filhos ou planejam uma nova gravidez, como se dessa forma a criança ou adolescente morto, estaria sendo esquecido. Silva (2009) afirma que, quando as mães têm outros filhos para cuidar, sofrem com a ambivalência de não se sentirem aptas para realizar esses cuidados devido a reconfiguração e questionamentos quanto ao seu papel de mãe, posto que haverá uma lacuna na relação familiar. Deste modo, a autora enfatiza que pode ser muito doloroso no início do luto ter que cuidar dos outros filhos, por serem eles, lembranças vivas do filho que morreu.

O luto materno gerou para as participantes alterações significativas em suas vidas tanto no papel de mãe, como também na rotina diária estabelecida com o filho antes de falecer. Os brinquedos que anteriormente davam "vida" à casa, foram substituídos pelo silêncio da ausência. Foram mudanças sobre representações de si mesma, da família, do cuidado com o outro e o desejo de se ocupar com o trabalho para "esquecer um pouco" aquele ser tão amado que não está mais junto delas. 
Por outro lado, algumas mães abordaram que os cuidados com os outros filhos foram estratégias de enfrentamento do luto, como se a necessidade de cuidado fosse um pouco suprida com o filho que ficou. Nesse mesmo sentido, três mães relataram a nova gravidez no processo de luto, como um acontecimento essencial que trouxe felicidade, mas, que em momento algum preencheria o espaço do filho falecido, pois de acordo com as mães, sempre existirá "um buraco no coração".

Depois de 5 meses do falecimento eu engravidei e durante a gravidez as pessoas me deram bastante carinho e cuidado e através da gravidez eu me sentia mais viva, isso me fortaleceu bastante. E depois, ele me distrai bastante, dá bastante alegria, e isso foi bastante importante (Mãe de uma Futura Psicóloga).

A chegada da L. foi uma alegria, não só para mim, mas para toda família. Não é que cobre porque o amor de um filho nunca é igual ao outro, a gente ama todos, mas não igualmente e nada ia tapar o buraco que eu tenho no coração. (Mãe de um Guerreiro)

Alguns dos estudos que abordam uma nova gestação subsequente à perda de um filho criança ou adolescente, retratam a ideia de uma gravidez na busca de alívio para a dor da perda. O vínculo com o novo filho pode estar impregnado pelas projeções e fantasias que não foram realizadas com o filho que morreu e em alguns casos, influenciam na construção da identidade do novo membro da família, tendo em vista que, para os estudiosos, esse filho pode ser uma personificação de memórias do filho falecido (Vidal, 2010). No entanto, o objetivo deste trabalho não é analisar o desabrochar de uma nova gravidez a partir desse ponto de vista, e sim, os benefícios que a concepção trouxe para a figura materna ressignificar o luto, percebidos através da vivacidade ao cuidar do novo filho, da construção de novas memórias de alegria, ressaltando a grande contribuição que a maternidade possivelmente fez ao ressurgir um novo papel de mãe carregado pela "fortaleza".

Outra perspectiva é apresentada quando as mães trazem que falar do filho diariamente, auxilia no enfrentamento.
Eu e ele (marido) para todo mundo que vem aqui, a gente tem que falar dele, porque quando vinham os clientes aqui, ele tinha que se fazer presente, as pessoas tinham que ver que ele estava ali (...) daí por isso, as pessoas chegam e eu tenho que dizer. Tipo, se eles não perguntam, eu tenho que dar um jeito de falar,

daí eu me sinto melhor. Parece assim que eu tenho que dizer que ele está ali de alguma forma dando uma fervidinha. (Mãe de um Sapeca)

Relembrar e conservar a memória dos filhos promove a garantia que eles jamais serão esquecidos entre as pessoas, mesmo com o decorrer do tempo, reafirmando o papel de mãe desse filho para sempre, visto que a perda emerge a possibilidade de rompimento da identidade conferida pela maternidade. A perpetuação da memória dos filhos, auxilia na amenização dos sentimentos negativos e representa um dos pilares da resiliência, trazendo amparo para dar continuidade à caminhada da vida (Soares et al., 2020).

Deus também surge como alicerce de enfrentamento nos relatos das mães, sendo fonte de obtenção de força em momentos de crise ou quando não há com quem conversar.

Então eu busquei muito a presença de Deus, eu já frequentava a igreja antes, aí busquei mais ainda.

Entendi, a partir do momento que tu entende a vontade de Deus, eu acho que é melhor para aceitar e lutar todos os dias. (Mãe de uma flor)

Segundo Gonçalves e Bittar (2016), as tradições religiosas e espirituais são criadoras de teorias sobre o sofrimento e acontecimentos após a morte, estando intimamente relacionadas à esperança, deste modo, ajuda a placar a angústia da finitude trazida pela morte. Cremasco et al. (2015) concordam com os autores citados ao descrever que, a crença em um ser supremo provedor de infinitas bondades e a busca por uma possibilidade paralela de continuidade de existência para o objeto perdido, podem ser comumente observadas na relação dos enlutados com a religiosidade e espiritualidade, e isso, promove o conforto sobre a suposta ideia de onde o filho está. Como apresenta o trecho: "Eu imagino que ela está bem, em um sono profundo, está descansando o que não descansou quando sofreu" (Mãe de uma Futura Psicóloga). 
Em algumas falas também é possível perceber um sentimento de ambivalência e incertezas em relação aos planos desse mesmo Deus que é força. Conforme o trecho: "Não era da vontade de Deus, o milagre existe, mas naquele momento ele não permitiu, por mais que dói a gente não tem entendimento dos planos de Deus e o plano que ele tinha era eu passar por isso" (Mãe de uma Futura Psicóloga).

Esses questionamentos são percebidos no luto pela manifestação da raiva, comum e natural após o despertar da fase de negação ou Isolamento. Bugdanovicz (2018) explica que a raiva é uma reação natural para a dor, neste momento, podem surgir atitudes de hostilidade e incertezas em relação a Deus por permitir que aquela pessoa partisse, à equipe de saúde por não conseguir salvar o filho, a si mesmo e até com as pessoas próximas ao pensar que esses não são capazes de entender o que está acontecendo.

A citação acima confirma-se com os estudos de Kubler-Ross (1996), ao analisar sobre o processo de morte em seus pacientes terminais e familiares. De acordo com Kubler-Ross (1996), em uma das fases do luto, a da Raiva, ocorrem atitudes de revolta, inveja, fúria e ressentimentos dirigidos principalmente aos familiares, amigos, Deus e equipe de saúde. Surgindo questionamentos do tipo "Por que comigo e não com outra pessoa?" "Por que Deus o levou?" Essa fase exige das pessoas que estão próximas tolerância e a compreensão de que se trata de uma manifestação de sofrimento psíquico, que necessita de escuta e aceitação.

Por mais que as estratégias para enfrentar o luto e torná-lo mais brando sejam semelhantes para as mães entrevistadas, a forma como cada uma vai criálas e atribuir seus significados será diferente. A nova gravidez para algumas entrevistadas reafirmou o seu papel materno, trouxe a alegria para preencher um pouco do silêncio, para outras foi a possibilidade de dar continuidade a uma etapa interrompida pela vida. Percebe-se que a estratégia de perpetuar a memória dos filhos fornece-lhes segurança e as tranquiliza na medida em que outras pessoas saibam que o filho existiu, assim como o fato de acreditar na crença que o este filho está bem e na existência de um ser superior que designa os planos para a vida, mesmo que em alguns momentos esses não são compreendidos, tornaram-se recursos para a resiliência e ressignificação do luto.

\section{Alteração no espaço da casa}

Sobre as alterações no espaço da casa, todas entrevistadas mencionaram que retiraram os pertences do quarto do filho ou fizeram a troca da mobília, principalmente do berço. Sobre as roupas, brinquedos e outros objetos, destacam que ficaram com algo de valor simbólico, consideradas especiais, como os cadernos da escola, uma roupa ou brinquedo favorito.

Então assim, fiz sacos de roupas e de brinquedos e fui dando para as crianças, só o que era mais especial para ela (filha) que eu fiquei para mim. Tentei desmontar aquele quarto porque não conseguia mais entrar ali, sabe o que é sentir uma paz? Uma leveza assim tão grande do ato que eu fiz (...).

(Mãe de uma Flor)

Apenas a "Mãe de um Sapeca" ainda guarda mais pertences do filho, mas afirma: "A gente teve que tirar todas as coisas mais visíveis dele para não doer tanto".

Segundo Silva (2009), a família pode se sentir insegura sobre o destino dos objetos pessoais do ente. Existe uma cobrança da sociedade ao preconizar que os familiares se desfaçam dessas coisas logo, como forma de se livrarem da dor da ausência ou mesmo da saudade, acreditando que dessa forma, fosse mais fácil esquecer as lembranças daquela pessoa. Algumas famílias optam por se desfazer deles imediatamente, após o falecimento, enquanto outras mantêm o armário, o quarto como antes, por até alguns anos. Não há um padrão de como isso deve ocorrer, pois é preciso respeitar o ritmo do processo de luto daquela família.

Para a autora a ausência é tão difícil de ser suportada que algumas famílias precisam manter as coisas, como uma forma de estreitar a conexão com a pessoa, principalmente nos primeiros meses. Como o passar do tempo, as mudanças acontecem passo a passo, e as lembranças importantes são mantidas, ao mesmo tempo em que os espaços vão sendo modificados naturalmente (Silva, 2009). Entretanto, quando os pais guardam todos os pertences sem ideia de se desfazer, caracteriza-se como um esforço para evitar a dor e adiá-la (Brandão \& Chalhub, 2009). 
Sobre o assunto, Franqueira et al. (2015) apresentam após uma pesquisa com mães enlutadas, que ter fotografias e alguns pertences do filho morto são de enorme importância. Os objetos são oportunidades que as mães têm de lembrar os filhos em vida e apresentá-los as pessoas que não os conheceram, sendo prova concreta de que o filho existiu.

Compreende-se a atitude das mães de alterar o espaço da casa ou de se desfazer das coisas, como um refúgio para minimizar a dor da saudade, dado que visualizar o tempo inteiro causaria maior sofrimento. Contudo, em alguns momentos buscam trazer o filho para o momento presente, quando desejam olhar e manipular esses pertences especiais guardados, é como se a presença viva do filho estivesse sendo sentida naqueles instantes, sendo uma forma que as mães encontraram para manter o vínculo com o filho falecido.

\section{O que dizer para alguém que acabou de perder o filho em razão do câncer}

De forma geral, as mães enfatizaram que a experiência será singular em cada indivíduo, mas que é muito "dolorida" e necessita de "força".

Não dá para dizer nada, é de cada um. É desejar força, é só o tempo! Tem que ter muito apoio dos filhos, da família, amigos. Mas cada um reage de uma maneira. Perder, só quem passa assim mesmo para saber, sabe? É uma coisa que não tem como descrever, a dor é de cada um e é uma dor terrível. Cada mãe sente diferente. (Mãe em Busca de Justiça)

As respostas adaptativas de mães enlutadas emergem da convergência de vários fatores, objetivos e subjetivos, que se relacionam com os significados construídos antes da morte do filho, constituindo-se em respostas e formas de expressar a perda de forma individual e singular. A morte de um filho afeta dimensões do passado, presente e futuro das mães, além de desencadear diferentes formas de vivenciar tal perda, provocando diferentes impactos na dimensão pessoal, no sistema familiar e no contexto social (Dahdah, 2019).

Freitas e Michel (2014) concordam com o autor acima ao destacar que o luto desperta nas mães uma infinidade de sentidos e reações, constituindo-se como uma experiência singular e particular visto que o luto materno no seu modo de apresentação vai abranger diferentes aspectos constituídos de formas diferentes em cada enlutada como: o horizonte histórico dessa relação; os significados e representações culturais e familiares diante da morte e do luto; a capacidade de enfrentar situações desorganizadoras, o ambiente acolhedor e, especialmente, as mudança advindas da perda.

A dor intensa surge como uma das principais expressões do luto materno, os relatos evidenciam que não há palavras capazes de diminuir o que cada mãe sente. É importante ressaltar que quando um filho morre de uma doença crônica, existem outros fatores que vão contribuir ou prejudicar o processo de luto saudável e isso torna o luto ainda mais peculiar. As crianças e adolescentes com câncer são submetidos há uma série de tratamentos que exigem o cuidado e zelo de outras pessoas, porém sabe-se que nem sempre essa assistência humanizada é oferecida nos hospitais e, para alguns pais, muitas situações vistas e vivenciadas durante o acompanhamento do tratamento do filho podem gerar ainda mais evocativos de dor, ao acreditarem que a história do filho poderia ter sido diferente se recebesse outros tipos de cuidados. Por outro lado, quando o filho recebe toda assistência com qualidade e amor, os pais sentem a sensação paz e conforto pois, tudo aquilo que era necessário fazer com relação a doença foi feito.

\section{Saúde psicológica atual}

Sobre a saúde Psicológica atual, duas mães consideram que estão bem, enquanto as demais relataram que há momentos muito difíceis, qualquer acontecimento principalmente as lembranças de acontecimentos marcantes, tornam-se estímulos para desestruturar a saúde mental. Conforme o trecho: “Hoje, eu estou melhor, só que existem épocas e momentos que é difícil. Tipo no aniversário do meu outro filho, eu fico feliz, mas fico me remoendo por dentro é aquela dor de que o outro poderia estar aqui junto" (Mãe em Busca de Justiça).

No que tange o assunto, Santos (2017) afirma que viver a dor do luto pode ser a mais profunda fonte de sofrimento para um ser humano, mesmo quando há condições psicológicas para o enfrentamento, acredita-se que o luto pode tornar o indivíduo temporariamente vulnerável do ponto de vista psíquico e, sob algumas condições pode favorecer o adoecimento físico e emocional. 
Na perda de familiar muito próximo, dificilmente a elaboração da morte se dá em menos de um ano. Alguns sinais podem sugerir o bem-estar psicológico como: a pessoa já é capaz de lembrar da pessoa que morreu sem manifestações físicas e emocionais intensas, ela readquire interesse pela vida, sente-se mais esperançosa com relação aos seu novos papéis e projetos. Porém, é fundamental compreender que o luto é um processo a longo prazo, sendo comuns e esperados, os episódios de recaída que demonstram novos sofrimentos psíquicos, em especial próximo a datas significativas como o aniversário da pessoa que morreu e datas festivas (Azevedo \& Siqueira, 2020).

Mesmo que tudo esteja bem e o luto se encaminha de uma forma saudável reencontrando novos sentidos e objetivos, uma mãe nunca supera a perda de um filho, o que acontece é a adaptação e convivência com a dor da saudade que se torna menos dolorida, a tristeza profunda vai dando lugar à novas experiências. Mesmo que passem anos, sempre vai existir o retorno às memórias do filho falecido que podem ser carregadas de sofrimento.

\section{Projeção para cinco anos}

Ao fazerem projeções de suas vidas para cinco anos, as entrevistadas planejam estar "formadas", "trabaIhando na área em que estudam" ou no "mesmo emprego e com os filhos maiores". Duas mães relataram também o desejo de mudar de casa ou modificar todo espaço em que residem atualmente. Conforme o trecho: "Formada, trabalhando na minha área, fazendo o que eu gosto. Com as minhas filhas maiorzinhas e com os sonhos e desejos que eu tenho dentro do meu coração realizado ou em projetos e feliz" (Mãe de um Guerreiro).

Nada substituirá o vazio de um filho, a saudade sempre haverá, mas isso não significa necessariamente que as pessoas perderam a capacidade de ser felizes, de almejar e lutar pela concretização de novos sonhos e saberes (Agnese et al., 2012). Diante das projeções futuras e o desejo de alcançar novos sonho, é possível perceber o conceito de Pulsão de Vida elaborado por Freud que "faz com que o indivíduo sinta vontade de satisfazer suas vontades, buscar o prazer e satisfação ( . . . )" (Oliveira, 2010, p. 63).
Os planejamentos e projeções feitos pelas mães mostram uma redefinição na vida delas, nota-se que o luto está sendo elaborado e o investimento da energia não está mais apenas naquele filho perdido.

\section{A ótica das mães sobre o que os filhos diriam se vissem como as mães estão atualmente}

Sanches (2012) pontua que o luto passa por caminhadas extremamente difíceis e densas, mas na etapa final, o vínculo afetivo com o filho que morreu será ressignificado e este ser amado será integrado à vida dos pais e pode exercer função de uma base segura e aconchegante, transmitindo uma sensação reconfortante, constituindo-se como ponto de referência valoroso para as vivências futuras. As mães entrevistadas trouxeram que os filhos estão "felizes", por essas "buscarem realizar desejos e sonhos" que em vida os filhos não tiveram o tempo suficiente para concretizá-los.

Acho que ela estaria feliz, ela é feliz porque muita coisa que eu não consegui fazer com ela eu fiz depois que ela faleceu, pode ser meio estranho, mas eu fiz. Um exemplo: ela tinha um casal de galinha e ela queria ver pintinhos, só que ela faleceu e não deu pintinhos, só que depois de um tempo eu fui lá e coloquei a galinha criar e fiz um monte de pintinhos, tenho até fotos, tudo é registrado. (Mãe de uma flor)

No momento em que um novo sentido positivo é atribuído para a experiência da perda do filho, o percurso dos que ficam com este ser querido na memória e "dentro do coração", torna-se menos doloroso. Como se o que era dotado de finitude se tornasse infinito, pois permanece nas lembranças das mães e consequentemente vivo dentro delas em forma de amor, podendo ser acessado sempre que a saudade se fazer presente (Vieira et al., 2017). Para Parkes (1998), o luto está sendo elaborado quando o enlutado consegue voltar-se novamente, ao mundo externo.

Um filho que morreu nunca será esquecido por sua mãe, ele estará em seus pensamentos, ações e conquistas. São laços que jamais serão rompidos. Haverá dias em que a tristeza se fará presente, mas com o passar do tempo o sentido da vida vai sendo reencontrado. Não há uma forma correta e única para chegar nesse momento, cada mãe alcançará no seu tempo ideal por meio de um trajeto construído por ela e para ela. 


\section{Considerações finais}

Diante dos resultados obtidos com as entrevistas, foi possível observar que a perda de um filho é uma experiência muito difícil e dolorosa para a mãe. Tratase de uma adaptação carregada por tristeza, culpa, sentimentos negativos e muita saudade. $\mathrm{Na}$ busca para o alívio da dor, as mães encontraram em seus familiares, amigos e na Casa Guido, apoio fundamental. Além disso, estar em contato com outras mães que vivenciaram a mesma situação e compartilhar suas angústias entendendo que nesse ambiente são acolhidas de forma segura e empática foi um aspecto positivo para ressignificar a nova vida sem o filho amado. Algumas mães encontraram na gravidez uma estratégia de sentir a vivacidade e reafirmar o seu papel de mãe. Outra contribuição positiva para o enfrentamento do luto refere-se à relação com a espiritualidade e a perpetuação da memória do filho.

Percebe-se que a alteração na rotina dessas mães passou por significativas modificações, algumas vistas pelas entrevistadas como benéficas, como voltar a realizar as atividades laborais, a escolha de uma nova profissão, principalmente para aquelas que escolheram uma área voltada para os cuidados em saúde. Por outro lado, algumas alterações foram consideradas ruins, o silêncio sentido pela falta do filho que morreu, o distanciamento afetivo dos outros filhos e as alterações na dinâmica familiar e identidade materna.

Embora algumas estratégias encontradas pelas mães possam ser analisadas do ponto de vista psicológico uma evitação à dor, é importante evidenciar que o luto é particular e único para cada indivíduo, mesmo que a situação seja semelhante. Desta forma, nenhuma estratégia pode ser considerada como inadequa$\mathrm{da}$, as respostas de adaptações encontradas pelas mães entrevistadas foram as melhores dentro da realidade, saúde mental e subjetividade de cada uma, trazendo benefícios para a reestruturação psíquica.

A principal limitação neste estudo foi de encontrar participantes dispostas a participarem da pesquisa, pois mesmo que a experiência de luto tenha acontecido a muito tempo, pode ser muito doloroso para algumas mães reviver essas memórias, enquanto para as que participaram, falar do filho é algo fundamental e que realizam diariamente.
Sugerem-se programas, grupos, que permitam falar sobre morte para a população em geral e principalmente para os profissionais da saúde, visando desmistificar a representação apenas negativa sobre o conceito de morte e luto e que possibilitem espaços de diálogos sobre como lidar com a situação, visto que, muitas pessoas não sabem o que dizer, ou fazer por uma pessoa enlutada. Outra sugestão é a realização de pesquisas voltadas para a escolha de uma profissão da saúde após a experiência de luto de algum familiar que faleceu de câncer ou outra doença.

A morte ainda é algo que se teme, talvez o ser humano nunca se sentirá totalmente preparado para se despedir de alguém que ama. Mas, quando a morte passa a ser vista com olhares de gratidão pelas oportunidades, ela se torna menos doída. Talvez a dor da saudade seja a mais hostil que exista, porém nada apagará as belas memórias compartilhadas com a pessoa, e isso é peça fundamental para prosseguir virtuosamente pelos caminhos futuros do luto, agradecendo por poder experimentar esses momentos. Não se trata apenas de um distanciamento entre vidas, refere-se à aproximação e ligação de corações que não se encontram mais juntos na vida terrena. O presente estudo visou contribuir com as demais famílias que vivenciam a mesma situação, assim como, servir de fundamentação na preparação de profissionais da saúde para dar suporte e apoio humanizado principalmente no tratamento da saúde mental das mães dessas crianças e adolescentes.

\section{Contribuições dos autores}

Frasson TC participou da concepção, delineamento, busca e análise dos dados da pesquisa, interpretação dos resultados e redação do artigo científico. Castro A participou da concepção, delineamento, análise dos dados da pesquisa, interpretação dos resultados, redação e revisão. Vidal GP participou da análise dos dados da pesquisa, interpretação dos resultados e redação do artigo científico.

\section{Conflitos de interesses}

Nenhum conflito financeiro, legal ou político envolvendo terceiros (governo, empresas e fundações privadas, etc.) foi declarado para nenhum aspecto do trabalho submetido (incluindo, mas não se limitando a subvenções e financiamentos, participação em conselho consultivo, desenho de estudo, preparação de manuscrito, análise estatística, etc.). 


\section{Referências}

Agnese, A. M. D., Batista, M. R., Oliveira, V. G., Rose, A. T., \& Lescano, N. (2012). Perda sem nome: como superar a ausência de pessoas queridas. Washington, DC: Organização Pan-Americana da Saúde.

Alves, K. M. C, Comassetto, I., Almeida, T. G., Trezza, M. C. S. F., Silva, J. M. O., \& Magalhães, A. P. N. (2016). A vivência dos pais da criança com câncer na condição de impossibilidade terapêutica. Texto e Contexto Enfermagem, 25(2), 1-9. https://doi.org/10.1590/0104$\underline{07072016002120014}$

Almeida, T. C. S., \& Mautoni, M. A. A. G. (2015). O luto pela morte do filho: espiritualidade e resiliência psicológica. CES Revista, 29(2), 158-175. https://seer.cesjf.br/index.php/ cesRevista/article/view/485

Andrade, M. L., Mishima-Gomes, F. K. T., \& Barbieri, V. (2017). Recriando a vida: o luto das mães e a experiência materna. Psicologia: Teoria Prática, 19(1), 21-32. http:// dx.doi.org/10.5935/1980-6906/psicologia.v19n1p33-43

Angst, R. (2009). Psicologia e resiliência: Uma revisão de literatura. Psicologia Argumento, 27(58), 253-260. https://periodicos. pucpr.br/index.php/psicologiaargumento/article/ view/20225

Arantes, A. C. Q. (2019). A morte é um dia que vale a pena viver. Sextante.

Azevedo, D. F., \& Siqueira, A. C. (2020). Terapia do Luto: intervenções clínicas na elaboração do processo de luto. Revista Farol, 9(9), 341-355. http://revistafarol.com.br/ index.php/farol/article/view/154

Bardin, L. (2011). Análise de conteúdo. Edições 70.

Barros, L. F., Santos, C. J. O., Moro, T. N. P., \& Jesus, V. M. F. (2017). Estudo de revisão da qualidade de vida e câncer infanto juvenil. Rede de Cuidados em Saúde, 10(1), 1-13. http:// publicacoes.unigranrio.edu.br/index.php/rcs/article/ view/3125

Brandão, F. R. M., \& Chalhub, A. (2009). A repercussão da morte de um filho na organização e estrutura familiar: uma revisão de literatura [Trabalho de Conclusão de Curso, Centro Universitário Jorge Amado]. Psicologia. https://www. psicologia.pt/artigos/textos/TL0184.pdf

Bromberg, M. H. P. F. (2000). A psicoterapia em situação de perdas e Iuto. Livro pleno.

Bugdanovicz, V. (2018). A morte no hospital e o papel do psicólogo. Anais do Evinci-UniBrasil, 4(2), 377-383. https://portaldeperiodicos.unibrasil.com.br/index.php/ anaisevinci/article/view/4073
Coelho Filho, J. F., \& Lima, D. M. A. (2017). Luto parental e construção identitária: compreendendo o processo após a perda do filho. Psicologia Argumento, 35(88), 16-32. http:// dx.doi.org/10.7213/psicolargum.35.88.AO02

Cremasco, M. V. F., Schinemann, D., \& Pimenta, S. O. (2015). Mães que Perderam Filhos: uma Leitura Psicanalítica do Filme Rabbit Hole. Psicologia: Ciência e Profissão, 35(1), 54-68. https://doi.org/10.1590/1982-3703002152013

Dahdah, D. F. (2019). O processo de elaboração do luto e as respostas ocupacionais no cotidiano de mães enlutadas [Tese de Doutorado, Universidade Federal de São Carlos]. Repositório UFSCAR. https://repositorio.ufscar.br/handle/ ufscar/11967

Franqueira, A. M. R., \& Magalhães, A. S. (2018). Compartilhando a dor: o papel das redes sociais no luto parental. Pesquisa Qualitativa, 6(11), 373-389. https://doi.org/10.33361/ RPQ.2018.v.6.n.11.172

Franqueira, A. M. R., Magalhaes, A. S., \& Feres-Carneiro, T. (2015). O luto pelo filho adulto sob a ótica das mães. Estudos de Psicologia, 32(3), 487-497. https://doi.org/10.1590/0103166X2015000300013

Freitas, J. L., \& Michel, L. H. F. (2014). A maior dor do mundo: o luto materno em uma perspectiva fenomenológica. Psicologia em Estudo, 19(2), 273-283. https://doi.org/10.1590/1413737222324010

Gil, A. C. (2008). Métodos e técnicas de pesquisa social (6a. ed.). Atlas.

Gomes, L. B., \& Gonçalves, J. R. (2015). Processo de luto: a importância do diagnóstico diferencial na prática clínica. Revista de Ciências Humanas, 49(2), 118-139. https://doi. org/10.5007/2178-4582.2015v49n2p118

Gonçalves, P. C., \& Bittar, C. M. L. (2016). Estratégias de Enfrentamento no Luto. Mudanças - Psicologia da Saúde 24(1), 39-44. https://doi.org/10.15603/2176-1019/mud. v24n1p39-44

Guido. Grupo pela Unidade Infantojuvenil de Onco-Hematologia. (2020). Missão. https://guido.org.br/a-instituicao/

Instituto Nacional do Câncer. (2020). Câncer infantojuvenil. https://www.inca.gov.br/estimativa/cancer-infantojuvenil

Kovács, M. J. (2009) Perdas e o processo de luto. In D. Incontri, \& F. S. Santos (Orgs.). A arte de morrer: visões plurais ( $2^{\mathrm{a}}$. ed. Volume 1). Comenius.

Kubler-Ross, E. (2000). Sobre a morte e o morrer (7a. ed.). Martins Fontes.

Laplanche, J., \& Pontalis, J. B. (2001). Vocabulário da Psicanálise. Martins Fontes. 
Mazer-Gonçalves, S. M., Valle, E. L. R. M., \& Santos, M. A. (2016). Significados da morte de crianças com câncer: vivências de mães de crianças companheiras de tratamento. Estudos de Psicologia, 33(4), 613-622. https://doi.org/10.1590/1982$\underline{02752016000400005}$

Medina, N. V. J., \& Takahashi, R. T. (2003). A busca da graduação em enfermagem como opção dos técnicos e auxiliares de enfermagem. Revista da Escola de Enfermagem da USP, 37(4), 101-108. https://doi.org/10.1590/S008062342003000400012

Oliveira, L. G. (2010). Eros e Thanatos: a pulsão de vida no conceito freudiano e o homo consumericus: A pulsão de vida no conceito Freudiano e o Homo Consumericus. Revista Labirinto, 14(10), 62-92. http://www.periodicos.unir. br/index.php/LABIRINTO/article/view/935

Parkes, C. M. (1998). Luto: Estudos sobre a perda na vida adulta. Summus.

Paula, D. P. S., Silva, R. C., Andrade, J. M. O., \& Paraiso, A. F. (2018). Câncer infantojuvenil do âmbito familiar: percepções e experiências frente ao diagnóstico. Revista Cuidarte, 10(1), e570. https://doi.org/10.15649/cuidarte.v10i1.570

Pereira, M. U. L., Gonçalves, L. L. M., Loyola, C. M. D., Anunciação, P. S., Dias, R. S., Reis, I. N., Pereira, L. A. S., \& Lamy, Z. C. (2018). Comunicação da notícia de morte e suporte ao luto de mulheres que perderam filhos recém-nascidos. Revista Paulista de Pediatria, 36(4), 422-427. https://doi. org/10.1590/1984-0462/;2018;36;4;00013

Rebelo, J. E., Lancman, S., \& Batista, M. P. P. (2017). Perspectivas sobre as estruturas não governamentais e a ação comunitária no apoio ao luto sadio em Portugal e o "Modelo Vivencial do Luto Sadio". Revista de Terapia Ocupacional da Universidade de São Paulo, 28(1), 1-8. https://www.revistas.usp.br/rto/article/ download/127282/141924/300309
Sanches, V. M. C. (2012). Luto materno e o vínculo com o filho substituto [Dissertação de Mestrado, Pontifícia Universidade Católica de São Paulo]. https://tede2.pucsp. $\underline{\mathrm{b} r / h a n d l e / h a n d l e / 15133 \text { ?locale=en }}$

Santos, M. V. N., \& Silva, P. M. (2016). Percepção da Morte por Câncer Infantil Segundo Profissionais, Familiares e Crianças. Uniceub. https://doi.org/10.5102/pic.n1.2015.5439

Santos, G. C. B. F. (2017). Intervenção do profissional de saúde mental em situações de perda e luto no Brasil. Revista $M$. Estudos sobre a morte, os mortos e o morrer, 2(3), 116-137. https://doi.org/10.9789/2525-3050.2017.v2i3.116-137

Silva, D. R. (2009). E a vida continua...: o processo de luto dos pais após o suicídio de um filho [Dissertação de Mestrado, Pontifícia Universidade Católica de São Paulo]. Repositório PUCSP. https://sapientia.pucsp.br/handle/handle/15898

Soares, L. G., Kuchla, E., Mazza, V. A., Gramazio S. L., Ferraz, M. I. R., \& Mattei, A. P. (2020). Mães de anjos: (re)vivenciando a morte do filho como estratégia de enfrentamento. Escola Anna Nery, 24(1), e20190030. https://doi.org/10.1590/21779465-EAN-2019-0030

Vidal, M. (2010). Gravidez após morte perinatal: sobre a relação da mãe com o bebê sobrevivente. Ciência \& Saúde Coletiva, 15(suppl. 2), 3185-3190. https://doi.org/10.1590/S1413$\underline{81232010000800023}$

Vieira, F., Pereira, D. G., \& Castro, E. H. B. (2017). A perda de um filho por câncer: sentidos e significados. Revista Amazônica, 9(2), 79-99. https://periodicos.ufam.edu.br/index.php/ amazonica/article/view/4530

Vinuto, J. (2014). A Amostragem em bola de neve na pesquisa qualitativa: um debate em aberto. Temáticas, 22(44), 203220. https://doi.org/10.20396/tematicas.v22i44.10977

Zanella, L. C. H. (2013). Metodologia de pesquisa (2a. ed.). Departamento de Ciências da Administração. 